\title{
Comparative Effects of Single Agent Rectal Diclofenac versus its Combination with Intramuscular Pentazocine on Post Caesarean Section Pain Relief in a Tertiary Institution in Southern Nigeria
}

\author{
Ngozi Joseph KWOSAH, Dagogo Alexander MACPEPPLE* \\ Department of Obstetrics and Gynecology, Rivers State University Teaching Hospital, Port-Harcourt, Nigeria \\ *Corresponding Author: Dagogo Alexander MACPEPPLE, Department of Obstetrics and Gynecology, \\ Rivers State University Teaching Hospital, Port-Harcourt, Nigeria, Email:dmacpepple@ymail.com
}

\begin{abstract}
Background: Caesarean section commonly causes moderate to severe pain in the first 24 hours after surgery with associated discomfort, increased risk of morbidity, delayed ambulation, difficulty in initiation of breastfeeding and prolonged hospital stay. Receiving adequate analgesia after caesarean section is very important as it provides subjective comfort, positive emotional status, greater patient's satisfaction as well as reduction in postoperative morbidity, hospital stay and cost.
\end{abstract}

Objectives: The objectives of this study were to compare the efficacy of single agent rectal diclofenac 100mg versus its combination with intramuscular pentazocine for pain management after caesarean section in Rivers State University Teaching Hospital, to compare the time to rescue analgesia among the two groups and also to identify the side effects of the drugs in the study population.

Methodology: This study was a randomized double blind clinical trial in Rivers State University Teaching Hospital, Port Harcourt, Rivers State, Nigeria. A total of 120 patients scheduled to undergo either elective or emergency caesarean section were studied. Group 'A' received rectal diclofenac and intramuscular placebo (unimodal group) while group ' $B$ ' received rectal diclofenac and intramuscular pentazocine (multimodal group). Socio-demographic information was collected via a structured profoma while a Visual Analog Scale (VAS) was used to assess the level of pain. Data were analysed using Statistical Package for Social Sciences (SPSS) software version 20 and statistical significance level was set at $p$ value of $<0.05$.

Results: The mean ages of respondents in unimodal and multimodal groups were $31.72 \pm 4.30$ years and $31.30 \pm 5.21$ years respectively. The difference in the median pain score and range was significant only at 8 hours between the unimodal $0(0-10)$ and the multimodal $0(0-5)$ groups. There was no significant difference before and after 8 hours. Although the mean time to first rescue analgesia was shorter in the unimodal group (147.50 \pm 60.07 minutes) as compared to the multimodal group (170.00 minutes), this difference was not statiscally significant ( $p$-value $=0.760)$. While one (1) patient made a second request, none of those in multimodal requested. There was no side effect noticed in either of the two groups.

Conclusion: The combined agents (diclofenac and pentazocine) had a superior analgesic effect to the single agent (diclofenac alone) when given as used in the study.

Keywords: Analgesia, caesarean section, diclofenac, multimodal, pentazocine, unimodal

\section{INTRODUCTION}

Caesarean section $(\mathrm{C} / \mathrm{S})$ is one of the most common surgeries done globally in obstetrics. This operation commonly induces severe pain, hence reducing the pain after $\mathrm{C} / \mathrm{S}$ is very important. The International Association for the Study of Pain (IASP) has noted that uncontrolled acute pain not only leads to discomfort and suffering, but can also have unwanted consequences, such as delayed wound healing, increased risk of morbidity, prolonged hospital stay, and the risk of developing chronic

ARC Journal of Gynecology and Obstetrics persistent pain [1]. In fact, in any post-caesarean section patient, early ambulation, breastfeeding and maternal bonding with the infant may be interfered by poor pain management [2].

Adequate pain management after caesarean section, using safe and effective analgesic drugs is a universal concern because pain relief is a fundamental human right [3]. Caesarean section patients have additional compelling reason to be provided with adequate pain relief, because thrombo-embolic diseases, which are increased during pregnancy could be prevented by early 
mobilization [4]. Besides, these patients need to be pain-free to care for their newborn and breastfeed them adequately. Adequate management of the pain after caesarean section cannot be overemphasized because most of the patients are young, healthy and active women who are eager to care for their infants. Since the initial post-operative hours and days are important for interaction between mother and newborn, pain should not interfere with the mother's ability to nurse her infant.

There is currently no gold standard for post caesarean pain management [5]. However, opioid analgesic drugs were commonly used for pain relief, but none of them is ideal [6]. Morphine and other opioids like fentanyl, sufentanil, diamorphine, hydromorphine, meperidine, buprenorphine and nalbuphine have been administered either through neuraxial or systemic approach in post-operative pain management [7]. The neuraxial could be intrathecal or epidural while the systemic could be oral, intramuscular or intravenous routes. There is also infiltration of surgical wound with local anaesthetic agents [8]. Intramuscular pentazocine, a partial agonist opioid is widely used in low resource countries like Nigeria and most centres in the developing world for postoperative analgesia with limited side effects [9]. The two most commonly used opioids in such regions are pentazocine and tramadol [10].

The analgesic effect of opioid is dependent on continuous stimulation of opiate receptors, inhibiting nociceptive impulses and the effect of a single injection persists for 4-6 hours [11]. Opioid analgesia can have negative impact on breastfeeding outcome such as reduction of babies' alertness and suckling vigor [12]. Central and peripheral side effects of opioids such as pain, hypotension, pruritus, nausea and vomiting, sedation, respiratory depression, dizziness, ileus, flashing and tachycardia restrict their use[13]. High cost, the risk of abuse and unavailability are other reasons for limited use of these drugs as routine analgesic medication after surgery. These limitations of opioids have led to the introduction of non-opioid analgesia.

Some non-opioid analgesic medications such as non-steroidal anti-inflammatory drugs (NSAIDs) have been found to reduce pain of uterine contractions by inhibiting prostaglandin synthesis through the inhibition of cyclooxygenase. Apart from direct antiinflammatory and analgesic effects, these drugs have an indirect effect on pain by reducing the chemical mediators of pain that make painful impulses leading to visceral pain relief. Diclofenac, a potent NSAID, in addition has an antipyretic property due to its direct depressant effect on the heat regulatory centre of the brain. It has been shown to provide effective pain relief in severe conditions such as dysmenorrhea and renal colic. It has also been shown to reduce opioid requirement in orthopedic, abdominal and gynecologic surgeries. Its onset of action is 30 minutes and the effect lasts for 6 hours [14].

Diclofenac does not interact with anesthetics, for example, it does not cause respiratory depression and it has been suggested that giving diclofenac (NSAIDs) before surgery begins may minimize the initiation of pain in the peripheral tissues and enhance their effectiveness as analgesics [15]. It is licensed for use during pregnancy and lactation [16]. When given on a regular basis, active substances have been detected in breast milk, but in such small quantities that it is not likely to cause undesirable effect [17]. Hence, diclofenac helps in early mobilization of the patient which reduces the risk of deep vein thrombosis and enhancing early postpartum recovery. In addition, a faster recovery post caesarean section means early establishment of breastfeeding which enhances maternal-infant bonding. Diclofenac could be administered parenterally, orally or as a suppository. Some side effects associated with diclofenac (NSAIDs) include: heartburn or dyspepsia and upper or lower gastrointestinal bleeding, ischemic colitis, proctitis, abdominal pain, local allergic reaction, itching and swelling [18]. There is a theoretical risk of postpartum hemorrhage with the use of NSAIDs as they cause prolongation of bleeding time and reduction of platelet aggregation. Generally, analgesic agents are many and the choice of the method of pain control are determined by drug availability, surgeon's preference, institutional protocols, patient's preference, available resources and financial considerations [19].

Childbirth and immediate breastfeeding initiation constitute a normal, continuous process. Hence, identifying effective, readily available and inexpensive analgesics will enhance obstetric practice in the area of study. There are numerous studies on post caesarean analgesia and most of the studies had been on single agent opioid versus multimodal 
comprising of opioid and an NSAID. However, there is no consensus on which is the best method. In Rivers State University Teaching Hospital, there is no written protocol for post caesarean section pain relief and most of the patients are indigent and cannot provide the required drugs for analgesia. Also, different authorities manage post caesarean section pain differently. Some use single agent diclofenac, some use single agent pentazocine while others use a combination of diclofenac and pentazocine. This study is designed to compare the effectiveness of single agent rectal diclofenac 100mg and its combination with intramuscular pentazocine $30 \mathrm{mg}$ for post caesarean section pain relief. This will enable us suggest a local protocol for our institution and possibly others in the country.

\section{AIM AND OBJECTIVES}

\subsection{Aim}

To compare the efficacy of single agent rectal diclofenac $100 \mathrm{mg}$ versus its combination with intra muscular pentazocine $30 \mathrm{mg}$ in the management of post caesarean section pain.

\subsection{Objectives}

1. To determine and compare the analgesic effect of single agent rectal diclofenac versus its combination with intramuscular pentazocine on post caesarean section pain.

2. To compare the time to rescue analgesia among the two groups (single agent rectal diclofenac versus its combination with intramuscular pentazocine in the treatment of post caesarean section pain)

3. To identify the side effects of the drugs in the two groups (single agent rectal diclofenac versus its combination with intramuscular pentazocine)

\subsection{Research Questions}

1. Is there any difference in the analgesic effect between single agent rectal diclofenac and its combination with intramuscular pentazocine?

2. Is there any difference in the time to rescue analgesia with single agent rectal diclofenac and its combination with intramuscular pentazocine?

3. What are the side effects of drugs used in the study population within 24 hours?

\subsection{Hypothesis}

\subsubsection{Null Hypothesis}

There is no significant difference in the analgesic effect of single agent rectal diclofenac versus its combination with intramuscular pentazocine on post caesarean section pain.

\subsubsection{Alternate Hypothesis}

There is significant difference in the analgesic effect of single agent rectal diclofenac versus its combination with intramuscular pentazocine on post caesarean section pain.

\section{Methodology}

\subsection{Study Area}

This study was conducted in the Department of Obstetrics \& Gynecology in Rivers State University Teaching Hospital in Port Harcourt, Rivers State. This hospital used to be known as Braithwaite Memorial Specialist hospital, until last year (2018), when it was converted to a Teaching hospital and renamed. Rivers State is one of the 36 states of Nigeria. It is one of the Niger Delta States in South-South Nigeria. Its population was 5, 198,716 as at the last census released in 2006. Port Harcourt is the state's capital and it is a metropolitan city. Rivers State University Teaching Hospital is a state owned tertiary hospital situated in the Government Reserved Area (GRA) phase 1 of Port Harcourt city. It provides all levels of health care services for Rivers and other neighboring states such as Bayelsa, Imo, Abia, Delta and Akwalbom States.

The Department of Obstetrics \& Gynecology is one of the major clinical departments of the hospital with ten consultants. It hasantenatal, gynecological, postnatal and labour wards. It also has a theatre with one gynecological and two obstetric suits. It runs five gynecological and five obstetrics clinics weekly. The department has five teams/units each of which consults twice a week. The department as at the last annual report in 2017 has a total of 12,049 antenatal attendees, 1,629 deliveries and 1,054 caesarean sections.

Each team has one gynecological clinic day, one antenatal clinic day, one theatre day, one consultant ward round and one call day in a week. Each day, a team covers the antenatal clinic while the next successive team covers the gynecological clinic. Each team takes one day call which could be any day except its antenatal 
clinic day and a week-end call after four weekends. Cases for elective caesarean operations are admitted from the clinic into the antenatal ward, prepared and operated on the team's theatre day. Cases for emergency caesarean sections are admitted and operated upon during the call. The department does an average of three caesarean sections (both elective and emergency) in a day.

\subsection{Study Design}

This research was a prospective, double blind randomized clinical trial.

\subsection{Study Population}

Pregnant women scheduled to undergo either elective or emergency caesarean section in Rivers State University Teaching Hospital.

\subsection{Inclusion Criteria}

1. Those who had elective or emergency caesarean section in Rivers State University Teaching Hospital during the period of study

2. Those whose operative time lasted less than 90 minutes

3. Those who gave informed consent

\subsection{Exclusion Criteria}

1. Those with known drug allergy

2. Those with medical co-morbidity

3. Those with epigastric pain or gastrointestinal bleeding

4. Those who had complications at surgery

\subsection{Sample Size}

Sample size was calculated using the formula for comparison of two groups [46]

$$
\mathrm{n}=\frac{(\mathrm{Z} \alpha+\mathrm{Z} \beta)^{2}\left(\mathrm{~S} 1^{2}+\mathrm{S} 2^{2}\right)}{(\mu 1-\mu 2)^{2}}
$$

n $\quad-\quad$ Minimum sample size

$\mathrm{Z} \alpha \quad-\quad$ Significant level of 95\%; corresponds to a value of 1.96

$\mathrm{Z} \beta \quad-\quad$ Power of study, set at $90 \%$; corresponds to a value of 1.28

S1 - Standard deviation of VAS scores from unimodal group in a similar

$$
\text { study }^{1}=0.67
$$

S2 - Standard deviation of VAS scores from multimodal group in a Similarstudy ${ }^{1}=0.48$

$\mu 1=\mu 2$ - Minimum mean difference detected between the two groups

(the effect size $)=0.4$

$$
\mathrm{n} \quad=\frac{(1.96+1.28)^{2}\left(0.67^{2}+0.48^{2}\right)}{0.4^{2}}
$$

$$
=\frac{(10.51)(0.449+0.230)}{0.16}
$$

$\mathrm{n} \quad=\quad 44.6$

Adjusted sample size $=\mathrm{n} / 1$ - attrition rate ${ }^{46}$

Where $\mathrm{n}=$ minimum sample size (44.6), attrition rate $=10 \%(0.1)$

$$
\begin{aligned}
& =44.6 / 1-0.1 \\
& =44.6 / 0.9 \\
& =49.6
\end{aligned}
$$

However, 60 subjects per group were recruited for this study, making a total of 120 subjects.

\subsection{Study Procedure}

An average of three caesarean sections were carried out daily (both elective and emergency sections) out of which one was randomized daily, giving a total of five per week. It therefore took twenty weeks to obtain the desired sample size. This study was carried out over a 5-month period (July to December 2017).

\subsection{Study Instrument}

The study proforma contained the following:

Socio-demographic information

Obstetrics Information such as parity and indications for the caesarean section

\section{Visual Analog Scale (VAS) \\ Time to rescue analgesia \\ Observed side effects}

The Visual Analog Scale (VAS) is a psychometric response scale for assessing pain. It is a measurement instrument for subjective characteristics or attitudes that cannot be directly measured. When responding to a VAS item, respondents specify their level of agreement to a statement by indicating a position along a continuous line between two end-points, for example, $0-10$ where zero indicates 'no pain' and 10 indicates 'maximal pain'. VAS is the most common pain scale for quantification of pain [47].

\subsection{Randomization}

The eligible subjects were allocated into groups using randomization. This involved the use of sealed opaque envelope containing papers labeled as either ' $A$ ' or 'B'. The subject selected a paper and was assigned to the group on the labeled paper - either of the two groups - 'A' or ' $B$ '. ' $A$ ' represents the unimodal group while the ' $\mathrm{B}$ ', multimodal group.

\subsection{Blinding}

The research was a double blind intervention study. The subjects were blinded to the type of 
drug being taken. The research assistants assessing the outcome in both groups were also blinded to the treatment received by the subjects. Hence both the subjects and the research assistants were blinded in the study. The drugs were administered by the trained research assistants.

\subsection{Study Protocol}

The drugs for the study were provided by the investigator. The ' $A$ ' group had rectal diclofenac100mg 8 hourly for 24 hours and intramuscular placebo 6 hourly for 24 hours while the 'B' group had rectal diclofenac $100 \mathrm{mg}$ 8 hourly for 24 hours and intramuscular pentazocine 30mg 6 hourly for 24 hours. Both the pentazocine and placebo were withdrawn early in the morning and added into their various packs and carefully stored in the refrigerator. Each pack contained fourdiclofenac 100mg suppositories (Voltaren@)

DiclofenacNatr. Paraadultos by Novartis, Zambia) and five $2 \mathrm{ml}$ syringes each had either $1 \mathrm{ml}$ of pentazocine $30 \mathrm{mg}$ (manufactured in India by BelcoPharma) or $1 \mathrm{ml}$ of placebo (injection water). The first dose commenced in the recovery room at time zero. Beforeeach administration of rectal diclofenac, the level of pain was assessed by the research assistant who will administer the drugs, then after the administration of the last drug in the pack, the patient was asked about her satisfaction with respect to the pain relief. Those who received rescue analgesia for breakthrough pain and who had side effects to the drugs used were identified and noted. These were the commonly used drugs in the treatment of post operative pain in our environment.
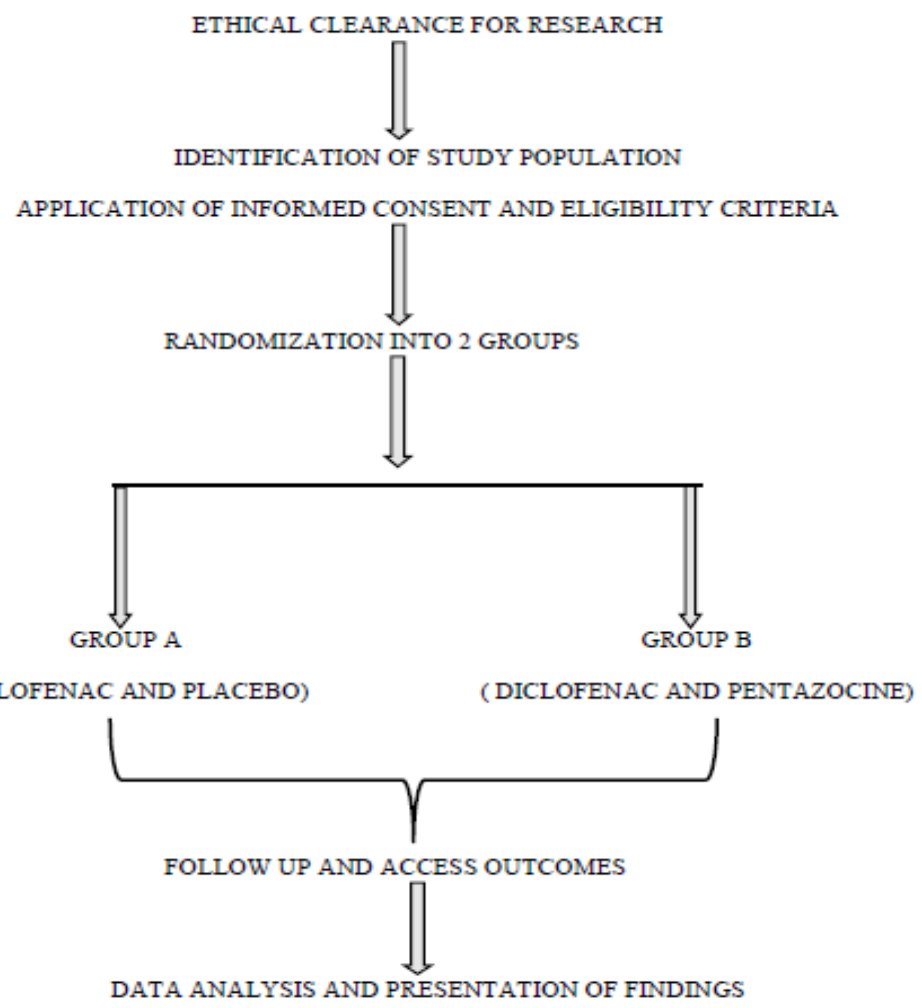

\subsection{Data Collection}

Data were collected via structured proforma. Following the informed consent, their sociodemographic characteristics and other eligibility characteristics were documented in a structured proforma for each participant and their folder tagged for identification.

\subsection{Outcome Measures}

The primary outcome variable was level of pain assessed using the Visual Analog Scale (VAS), scored $0-10$. Zero being 'no pain' and 10 indicating 'maximal pain'. The secondary outcome variables were the duration of analgesia post-operatively expressed in hours, the frequency of breakthrough analgesia and the presence of side effects.

Three research assistants who were chosen from the junior residents in the department of Obstetrics and Gynecology were trained for 5 days on how to administer the consent form, questionnaire to obtain the socio-demographic information and indication for surgery, how to assess pain using Visual Analog Scale, how to administer the drugs and how to assess patient's 
satisfaction after the last drug in the pack has been administered.

\subsection{Data Analysis}

This was done using the Statistical Package for Social Sciences (SPSS) software version 20. The data were presented as tables and charts as appropriate. Qualitative variables like sex, educational level were expressed as frequencies and projections. The data were tested for normality using Kolmogorov-Smirnov statistics. Quantitative variables that are normally distributed were summarized as means and standard deviation; and the differences in means between the two groups was compared using the studient's t-test, while non-normally distributed quantitative variables were summarized using medians and ranges; and the Mann-Whitney $U$ test was applied to compare differences in medians between the two groups, chi square test and fisher's Exact test were used as appropriate to determine statistically significant differences in proportions between the groups. A p-value of less than 0.05 was considered statistically significant.

\subsection{Ethical Consideration}

Ethical approval for the study was obtained from the Rivers State Health Research and Ethics Committee in Port Harcourt. In designing the study, the following ethical issues were put into consideration. Participation was voluntary as an informed consent to participate and withdraw from the study was provided. The purpose of the study was explained to the participants. Consenting participants were made to sign the consent form. They were fully informed of their liberty to withdraw from the

Table1. Comparison of mean characteristics between unimodal and multimodal groups

\begin{tabular}{|l|l|l|l|l|}
\hline \multicolumn{1}{|c|}{ Variables } & $\begin{array}{c}\text { Unimodal } \\
\text { (Diclofenac only) } \\
\text { Mean } \pm \text { S.D }\end{array}$ & $\begin{array}{c}\text { Multimodal } \\
\text { (Diclofenac and Pentazocin }) \\
\text { Mean } \pm \text { S.D }\end{array}$ & \multicolumn{1}{|c|}{$\mathbf{t}$} & \multicolumn{1}{|c|}{ P-value } \\
\hline Age $($ years) & $31.72 \pm 4.30$ & $31.30 \pm 5.21$ & 0.478 & 0.634 \\
\hline BMI $\left(\mathrm{kg} / \mathrm{m}^{2}\right)$ & $29.85 \pm 4.86$ & $29.54 \pm 5.78$ & 0.302 & 0.763 \\
\hline Gestational age(weeks) & $38.40 \pm 2.26$ & $37.98 \pm 2.54$ & 0.947 & 0.346 \\
\hline
\end{tabular}

SD - Standard deviation

The highest proportion of respondents in unimodal group $44(73.3 \%)$ and multimodal group 38 (63.4\%) were aged $25-34$ years while the least proportion in both groups $(3.3 \%$ and $8.3 \%$ in unimodal and multimodal respectively) were aged $15-24$ years. The differences in proportions of the age categories across unimodal and multimodal groups were not significant $(\mathrm{p}$ value $=0.401)$. The parity range study without prejudice to their usual expected standard of care.

\subsection{Confidentiality of Data}

All information including history, physical findings and results obtained from the participants were kept strictly confidential. The participants were assured that their identity will be kept in confidence by the researcher.

\subsection{Beneficience to Participants}

No participant was made to pay for the analgesic drugs used for the study. The result from this study will enhance the post-operative pain management in the department and enable the department come up with a protocol on post operative pain relief that will benefit all patients alike.

\section{RESUlT}

\subsection{Socio-Demographic Characteristics of Respondents}

This study had a total of 120 women, of which 60 each were assigned to unimodal and multimodal groups. The mean ages of respondents in unimodal and multimodal groups were $31.72 \pm 4.30$ years and $31.30 \pm 5.21$ years respectively. The difference in the mean ages was not significant ( $\mathrm{p}$ value $=0.634$ ) as shown in Table 1. The difference in the mean Body Mass Index (BMI) across unimodal (29.85 \pm $\left.4.56 \mathrm{~kg} / \mathrm{m}^{2}\right)$ and multimodal $(29.54 \pm 5.78$ $\mathrm{kg} / \mathrm{m}^{2}$ ) was not significant $(\mathrm{p}$ value $=0.763$ ) Also, the difference in the mean gestational age $(38.40 \pm 2.26$ weeks and $37.98 \pm 2.54$ weeks in unimodal and multimodal groups respectively) was not significant $(\mathrm{p}$ value $=0.346$ ) for both groups was [1-6] and the median parity of the respondents was [2] in both groups. The highest proportion of respondents of unimodal group $34(56.7 \%)$ and multimodal group 33 $(55.0 \%)$ were multiparous women while 22 $(36.7 \%)$ and $25(41.7 \%)$ of the women in unimodal and multimodal groups respectively were primiparous. The least proportion of the respondents were grand multiparous in both 
groups $(6.6 \%$ and $3.3 \%$ in unimodal and multimodal respectively). The differences in the proportion of the categories of parity by group

Table2. Socio-demographic characteristics of respondents were not significant ( $\mathrm{p}$ value $=0.684$ ) as shown in Table 2.

\begin{tabular}{|c|c|c|c|}
\hline Variables & $\begin{array}{c}\text { Unimodal } \\
\text { (Diclofenac only) } \\
\mathbf{N}=\mathbf{6 0} \\
\mathbf{n}(\%)\end{array}$ & $\begin{array}{c}\text { Multimodal } \\
\text { (Diclofenac and Pentazocin) } \\
\mathbf{N}=60 \\
\mathbf{n}(\%)\end{array}$ & $\begin{array}{c}\text { Total } \\
\text { N=120 } \\
\text { n }(\%)\end{array}$ \\
\hline \multicolumn{4}{|l|}{ Age (years) } \\
\hline $15-24$ years & $2(3.3)$ & $5(8.3)$ & $7(5.8)$ \\
\hline $25-34$ years & $44(73.3)$ & $38(63.4)$ & $82(68.3)$ \\
\hline \multirow[t]{2}{*}{$35-44$ years } & $14(23.2)$ & $17(28.3)$ & $31(25.9)$ \\
\hline & \multicolumn{2}{|c|}{ Fishers exact test $=1.951 ; p$-value $=0.401$} & \\
\hline \multicolumn{4}{|l|}{ Marital status } \\
\hline Single & $5(8.3)$ & $6(10.0)$ & $11(9.2)$ \\
\hline \multirow{2}{*}{ Married } & $55(91.7)$ & $54(90.0)$ & $109(90.8)$ \\
\hline & \multicolumn{2}{|c|}{ Chi square $=0.100 ; p$-value $=0.752$} & \\
\hline \multicolumn{4}{|l|}{ Parity } \\
\hline Primiparous (Para 1) & $22(36.7)$ & $25(41.7)$ & 47 (39.2) \\
\hline Multiparous (Para 2-4) & $34(56.7)$ & $33(55.0)$ & $67(55.8)$ \\
\hline Grand multiparous (Para $\geq 5$ ) & $4(6.6)$ & $2(3.3)$ & $6(5.0)$ \\
\hline
\end{tabular}

Fishers exact test $=0.875 ;$-value $=0.684$

Emergency caesarean sections had higher proportion in both unimodal $39(65.0 \%)$ and multimodal $35(58.3 \%)$ while $21(35.0 \%)$ and 25 $(41.7 \%)$ of the unimodal and multimodal groups

Table3. Type of caesarean section across the groups respectively were elective caesarean sections. The difference in proportion of the type of caesarean section across the groups was not significant $(\mathrm{p}$ value $=0.453)$ as shown in Table 3 .

\begin{tabular}{|l|l|l|l|}
\hline \multicolumn{1}{|c|}{ Type of caesarean section } & \multicolumn{1}{|c|}{$\begin{array}{c}\text { Unimodal } \\
\text { (Diclofenac only) } \\
\mathbf{n}(\boldsymbol{\%})\end{array}$} & \multicolumn{1}{|c|}{$\begin{array}{c}\text { Multimodal } \\
\text { (Diclofenac and Pentazocin) } \\
\mathbf{n}(\boldsymbol{\%})\end{array}$} & $\begin{array}{c}\text { Total } \\
\mathbf{n}(\%)\end{array}$ \\
\hline Elective & $21(35.0)$ & $25(41.7)$ & $46(38.3)$ \\
\hline Emergency & $39(65.0)$ & $35(58.3)$ & $74(61.7)$ \\
\hline Total & $\mathbf{6 0}(\mathbf{1 0 0 . 0})$ & $\mathbf{6 0}(\mathbf{1 0 0 . 0})$ & $\mathbf{1 2 0}(\mathbf{1 0 0 . 0})$ \\
\hline
\end{tabular}

Chi square $=0.564 ; p$ value $=0.453$

\subsection{Comparison of Analgesic Effect between the Unimodal and Multimodal Groups}

At zero hour, the median pain score and ranges were $0(0-10)$ and $0(0-10)$ among respondents in unimodal and multimodal groups respectively. The difference in the median pain score across groups at zero hour was not significant $(p$ value $=0.118)$. At 8 hours, the median pain score and ranges were $0(0-10)$ in the unimodal group and $0(0-5)$ in the multimodal group, this difference in the median pain score was statistically significant $(\mathrm{p}$ value $=$ $0.033)$.

At 16 and 24 hours, the differences in the median pain score and ranges across the groups were not statistically significant as shown in the table 4.

Table4. Comparison of median pain scores between unimodal and multimodal groups at time of follow-up

\begin{tabular}{|l|l|l|l|l|}
\hline \multicolumn{1}{|c|}{ Time } & \multicolumn{1}{c|}{$\begin{array}{c}\text { Unimodal } \\
\text { (Diclofenac only) } \\
\text { Median pain score }\end{array}$} & $\begin{array}{c}\text { Multimodal } \\
\text { (Diclofenac and Pentazocin ) } \\
\text { Median pain score }\end{array}$ & $\begin{array}{c}\text { Mann- } \\
\text { Whitney U }\end{array}$ & \multicolumn{1}{c|}{ P-value } \\
\hline 0 hour & $0(0-10)$ & $0(0-10)$ & 1567.500 & 0.118 \\
\hline 8 hours & $0(0-10)$ & $0(0-5)$ & 1471.500 & $0.033^{*}$ \\
\hline 16 hours & $0(0-7)$ & $0(0-5)$ & 1531.500 & 0.092 \\
\hline 24 hours & $0(0-6)$ & $0(0-3)$ & 1612.000 & 0.154 \\
\hline
\end{tabular}

*Statistically significant

The mean pain scores were consistently lower in the multimodal group in comparison to the unimodal group across the follow-up period as shown in Figure 1. 


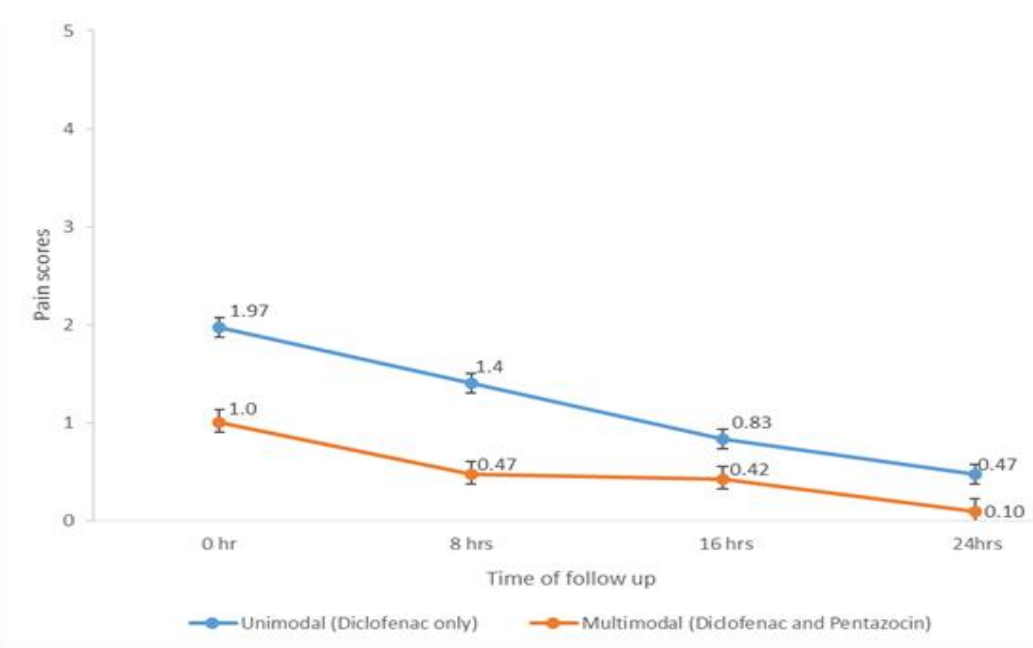

Figure1. Error bar showing the mean pain scores of unimodal and multimodal groups in the study

\subsection{Comparison of the Time to Rescue Analgesia between the Two Groups}

The mean time to first rescue analgesia which was recorded within the first 8 hours post operative period were $147.50 \pm 60.07$ minutes and 170.00 minutes for unimodal and multimodal groups respectively. Although the mean time was shorter in the unimodal group in comparison to the multimodal group, the difference was not statistically significant $(\mathrm{p}$ value $=0.760$ ). While the unimodal group had mean time to second rescue analgesia of 250.00 minutes (one patient), none of the respondents in the multimodal groups requested for second rescue analgesia.

Third rescue analgesia was not requested by any of the respondents of the two groups as shown in Table 5.

Table5. Comparison of mean time to request for analgesia between unimodal and multimodal groups

\begin{tabular}{|l|l|l|l|l|}
\hline \multicolumn{1}{|c|}{ Request for rescue analgesia* } & $\begin{array}{c}\text { Unimodal } \\
\text { (Diclofenac only) } \\
\text { Mean } \pm \text { S.D }\end{array}$ & $\begin{array}{c}\text { Multimodal } \\
\text { (Diclofenac and Pentazocin ) } \\
\text { Mean } \pm \text { S.D }\end{array}$ & t & P-value \\
\hline Time of first request (mins) & $147.50 \pm 60.07$ & $170.00 \pm 0.00$ & 0.335 & 0.760 \\
\hline Time of second request (mins) & $250.00 \pm 0.00$ & - & - & - \\
\hline
\end{tabular}

\section{S.D - Standard deviation}

*None of the respondents in the multimodal group had second rescue analgesia and none of the respondents in both groups had third rescue analgesia

Figure 2 shows the proportion of those who requested rescue analgesia in both the unimodal and multimodal groups. Four respondents
$(6.7 \%)$ in the unimodal group and 1 respondent $(1.7 \%)$ in the multimodal group requested for first rescue analgesia in the first 8 hours. A second rescue analgesia was requested by a respondent $(1.7 \%)$ in the unimodal group while none $(0.0 \%)$ in the multimodal requested a second rescue analgesia.

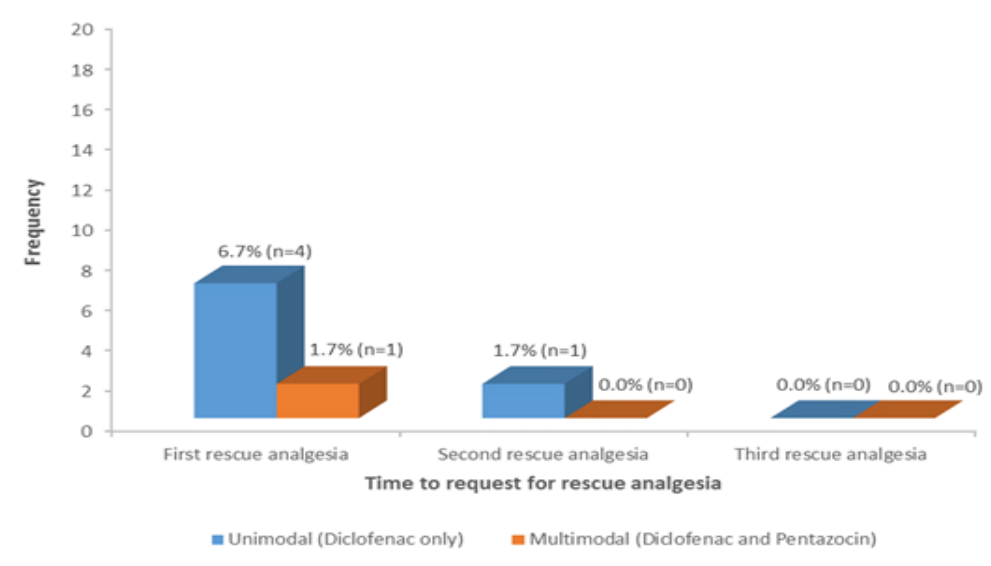

Figure2. Proportion of respondents that requested for rescue analgesia in unimodal and multimodal groups 


\subsection{Comparison of the Level of Satisfaction between the Two Groups}

A comparison of the level of participants' satisfaction experienced during the first 24 hours post operatively revealed that there was no statistically significant difference between the two groups $(\mathrm{p}$ value $=0.224)$. A higher proportion of respondents $44(73.3 \%)$ which was the same in both groups were satisfied.

Table6.Comparison of the level of satisfaction among respondents in unimodal and multimodal groups

\begin{tabular}{|l|l|l|l|}
\hline \multicolumn{1}{|c|}{ Level of satisfaction } & \multicolumn{1}{c|}{$\begin{array}{c}\text { Unimodal } \\
\text { (Diclofenac only) } \\
\mathbf{n}(\%)\end{array}$} & \multicolumn{1}{c|}{$\begin{array}{c}\text { Multimodal } \\
\text { (Diclofenac and Pentazocin) } \\
\mathbf{n}(\%)\end{array}$} & \multicolumn{1}{c|}{$\begin{array}{c}\text { Total } \\
\mathbf{n}(\%)\end{array}$} \\
\hline Dissatisfied & $6(10.0)$ & $2(3.3)$ & $8(6.7)$ \\
\hline Undecided & $1(1.7)$ & $0(0.0)$ & $1(0.8)$ \\
\hline Satisfied & $44(73.3)$ & $44(73.3)$ & $88(73.3)$ \\
\hline Very satisfied & $9(15.0)$ & $14(23.0)$ & $23(19.2)$ \\
\hline Total & $\mathbf{6 0 ( 1 0 0 . 0 )}$ & $\mathbf{6 0 ( 1 0 0 . 0 )}$ & $\mathbf{1 2 0}(\mathbf{1 0 0 . 0})$ \\
\hline
\end{tabular}

Fisher's exact test $=3.902 ; p$ value $=0.224$

\subsection{Occurrence of Side Effects}

Sedation, hypotension, pruritus, dizziness, nausea, vomiting, heartburn or dyspepsia, gastrointestinal bleeding and other side effects of pentazocine or diclofenac were not observed in any of the respondents in the two groups. Respiratory depression, poor suckling, excessive sleep or neonatal jaundice did not occur among the babies of the mothers in the two groups.

\section{DISCUSSION}

Post caesarean section analgesia is indispensible for reducing post-operative stress, providing subjective comfort and facilitating postoperative recovery. This study compared the post caesarean analgesic effect between single agent diclofenac (unimodal) and its combination with pentazocine (multimodal). In this study, the maternal characteristics (age, parity and BMI) were similar at baseline in both the unimodal and multimodal groups. Hence, revealing that both groups were comparable.

Noteworthy, limited studies exist in the literatures comparing diclofenac as a single agent analgesic after caesarean section and its combination with pentazocine even though these drugs and others are widely used for this purpose. Diclofenac was chosen as a single agent in this study because of its good analgesic properties, non-sedative and lack of the respiratory depressant effect seen in opioids. It has actually been found to be better when compared with paracetamol as was seen in the study by Munishanka et al where the analgesic effects of both drugs were compared in comparison to $9(15.0 \%)$ in the multimodal and unimodal groups respectively were very satisfied. Only one respondent $(1.7 \%)$ in the unimodal group was undecided and none $(0.0 \%)$ in the multimodal group. The unimodal group had a higher number of respondents who were dissatisfied $6(10.0 \%)$ in comparison to the multimodal group $2(3.3 \%)$ as shown in Table 6.
More of the respondents $14(23.0 \%)$ in

management of post caesarean pain [31]. Similarly, diclofenac was also noted to have better analgesic property than pethidine in the study by Al-hakim and Shahraki where they were compared in post caesarean pain management. In addition to inhibiting prostaglandin synthesis, NSAIDs (e.g diclofenac) removes chemical mediators of pain - a property which opioids do not have. Several other studies supported the view that diclofenac has better analgesic property than opioids in post caesarean pain management [31-33]. This conclusion could be because opioids have sedative effects which make the patient unable to care for her infant in the immediate postpartum period. In addition, the opioids are drugs of addiction and as a result have high tendency of abuse.

Hence, the finding of a statistically significant difference in the median pain score between group A (diclofenac only) and group B (diclofenac and pentazocine) within the first 8 hours post caesarean section in index study reveals a better pain control in the multimodal group in comparison to the unimodal group. One plausible explanation to this phenomenon could be the synergistic effect of combination of two different analgesics with different mechanisms of action, with the opioid acting on the central nervous system, while NSAIDs (e.g. diclofenac) inhibit prostaglandin synthesis from arachidonic acid by inhibiting cyclooxygenase, thus reducing inflammation [48]. Thus multimodal strategies help achieve better pain 
relief while using lower doses of opioids and potentially fewer adverse effects, by affecting pain through different mechanisms of action and pathways [49]. This finding is in keeping with similar studies by Adetunji et al [1], Simeon et al [10], and Natalia et al [23] who in contract to this study, compared multimodal (opioid and NSAID) with unimodal (opioid only) in post caesarean section pain relief. These studies [1, $10,23]$ along with the present study demonstrated that combining two drugs of different mechanism of action had better analgesic effect than a single agent. However, unlike the present study, which used NSAID as a single agent, these studies [1, 10, 23] used pentazocine.

Although, the mean time to first rescue analgesia in the unimodal group was not significantly different from the multimodal group, only the unimodal group sort and had a second rescue analgesia. This possibly connotes that the analgesic effects on both groups are comparable, however, the multimodal group appear to be superior. Also the finding of no significant difference in the meantime to first rescue analgesia possibly exposes the usefulness of NSAIDs as a single analgesic agent in low resource settings.

The side effects of pentazocine or diclofenac were not noticed in this study population probably because the duration of the study was for only 24 hours or the use of low dose pentazocine in the multimodal group. The recommended dose of pentazocine when used alone for pain management is usually [30-60] mg every 3 to 4 hours intramuscularly not exceeding 60mg per dose (maximum: $360 \mathrm{mg}$ per day) [49]. The choice of rectal diclofenac when compared to other routes of administration is worthy of note as this rectal route avoids rare but hazardous complications of intramuscular diclofenac such as necrotizing fasciitis, anaphylactic shock and upper limb gangrene $[50,51]$. Diclofenac is safe in the peripartum period, being FDA Category B [49]. Furthermore, one concern regarding use of diclofenac in the peripartum period is the potential for gastric ulceration and nephrotoxicity events in a population that is already at a high baseline risk of gastric or duodenal ulcer or chronic renal disease [49]. As a matter of fact, this should be kept in mind when considering use of diclofenac. Contrary to some studies [38-45] where side effects of the drugs were noticed, this present study did not show any side effect in either the mothers or neonates possibly because the drugs were given for only 24 hours. This finding of no side effect agrees with a study by Adamou et al [23].

\section{CONClusion}

1. The multimodal group had a superior analgesic effect in comparison to the unimodal group.

2. The time to first rescue analgesia between the two groups showed no significant difference, however none of the women in the multimodal group made second request for rescue analgesia

3. No side effect was observed in both groups within the period of study.

\section{RECOMMENDATIONS}

1. Obstetricians and Gynaecologists should ensure that effective post caeasareanpain management is given to all patients.

2. Government should support a prospective multi centered double blind controlled trial comparing the effectiveness, time to rescue analgesia and side effects of the agents used in this study and for longer period to derive a stronger evidence and generalization.

\section{LIMITATIONS}

This research was a single-centre study, hence the limiting extent of generalizeability of the findings. It is capital intensive.

\section{REFERENCES}

[1] Adeniji AO, Atanda O. Randomized comparison of effectiveness of unimodal opioid analgesia with multimodal analgesia in postcesarean section pain management. J Pain Res. 2013;6:419-424

[2] Ebirim LN, Buowari OY, Ghosh S. Physical and psychological aspects of pain in obstetrics. Pain in perspective InTech 2012.

[3] Brennan F, Carr DB, Cousins M. Pain management: A fundamental human right. Anesth Analg. 2007;105:205-221

[4] Saunders KW, Dunn KM, Merrill JO, Sullivan M, Weisner C, Braden JB, et al. Relationship of sopioid use and dosage levels to fractures in older chronic pain patients. J Gen Intern Med. 2010;25:310-315

[5] Kanazi GE, Aouad MT, Abdallah FW, Khatib MI, Adham AM, Harfoush DW, et al. The analgesic efficacy of subarachnoid morphine in comparison with ultrasound-guided transversus 
abdominis plane block after cesarean delivery: A randomized controlled trial. Anesth Analg. 2010;111:475-481

[6] Koes BW, van Tulder M, Lin C-WC, Macedo LG, McAuley J, Maher C. An updated overview of clinical guidelines for the management of non-specific low back pain in primary care. Eur Spine J. 2010;19:2075-2094

[7] Carvalho B, Butwick A. Postoperative analgesia: Epidural and spinal techniques. In: Chestnut D, Wong C, Tsen L, Ngan Kee W, Beilin Y, Mhyre J (eds). Chestnut's obstetric Anesthesia Principles and Practice. Fifth edition. Elsevier Saunders. 2014:621-61

[8] Ventham N, Hughes M, O'Neill S, Johns N, Brady R, Wigmore S. Systematic review and meta-analysis of continuous local anaesthetic wound infiltration versus epidural analgesia for postoperative pain following abdominal surgery. Br J Surg. 2013;100:1280-1289

[9] Bichave A, Aggarwal A, Shinde P, Pimple S. Ain-2 evaluation of anti-inflammatory activity of hyoscine butyl bromide in albino wistar rats. Indian J Pharmacol. 2015;47:57-177

[10] Olateju SO, Adenekan AT, Olufolabi AJ, Owojuyigbe AM, Adetoye AO, Ajenifuja KO, et al. Pentazocine versus pentazocine with rectal diclofenac for postoperative pain relief after cesarean section-a double blind randomized placebo controlled trial in a low resource area. Middle East J Anaesthesiol.2016; 23(4), 443-448.

[11] Salvemini D. Inhibition of opioid antinociceptive tolerance and withdrawal in nociceptive pain therapy. United States patent application US 14/496,030. 2015.

[12] Jankovic K. Pharmacological management of pain in obstetrics. Guide to Pain Management in Low-Resource Settings. InKopf A, Patel NB (eds). Guide to Pain Management in LowResource Settings. IASP, Seattle, 2010; 123

[13] Smith HS, Pappagallo M. Essential pain pharmacology: The prescriber's guide. Cambridge University Press; 2012.

[14] Aliaga L. The secrets of pain relief: Natural remedies that will end your suffering. Skyhorse Publishing, Inc.; 2016.

[15] McCleane G. Topical application of analgesics: A clinical option in day case anaesthesia? Curr Opin Anaesthesiol. 2010; 23:704-707

[16] Montgomery A, Hale, The Academy of Breastfeeding Medicine. ABM clinical protocol \#15: Analgesia and anesthesia for the breastfeeding mother, revised 2012. Breastfeeding Medicine. 2012;7:547-553

[17] Hutchinson S, Marmura MJ, Calhoun A, Lucas S, Silberstein S, Peterlin BL. Use of common migraine treatments in breast-feeding women:
A summary of recommendations. Headache 2013;53:614-627

[18] Session I. Sunday, 22 september 2013. J Gastroenterol Hepatol. 2013;28:23-693

[19] Simavli S, Kaygusuz I, Kinay T, Baylan AA, Kafali H. Bupivacaine-soaked absorbable gelatin sponges in caesarean section wounds: Effect on postoperative pain, analgesic requirement and haemodynamic profile. Int $\mathbf{J}$ Obstet Anesth. 2014;23:302-308

[20] Walch K, Unfried G, Huber J, Kurz C, van Trotsenburg M, Pernicka E, et al. Implanon ${ }^{\circledR}$ versus medroxyprogesterone acetate: Effects on pain scores in patients with symptomatic endometriosis - a pilot study. Contraception. 2009;79:29-34

[21] Munishankar B, Fettes P, Moore C, McLeod G. A double-blind randomised controlled trial of paracetamol, diclofenac or the combination for pain relief after caesarean section. Int J Obstet Anesth. 2008;17:9-14

[22] Al-hakim NH, Alidreesi Z. The effect of local anaesthetic wound infiltration on postoperative pain after caesarean section. J Surg Pak. 2010;15:131-134

[23] Shahraki AD, Jabalameli M, Ghaedi S. Pain relief after cesarean section: Oral methadone vs. Intramuscular pethidine. J Res Med Sci. $2012 ; 17: 143$

[24] Chou R, Gordon DB, de Leon-Casasola OA, Rosenberg JM, Bickler S, Brennan T, et al. Management of postoperative pain: A clinical practice guideline from the american pain society, the american society of regional anesthesia and pain medicine, and the american society of anesthesiologists' committee on regional anesthesia, executive committee, and administrative council. J Pain. 2016;17:131-157

[25] Eleje GU, Egeonu RO, Obianika CE, Mbachu II, Okohue JE, Osuagwu IK et al. Diclofenac and pentazocine versus pentazocine alone for post-operative analgesia in cesarean section. Int J Med Health Dev. 2015;20

[26] Adamou N, Tukur J, Muhammad Z, Galadanci H. A randomised controlled trial ofopioid only versus combined opioid and non-steroidal anti inflammatory analgesics forpain relief in the first 48 hours after caesarean section. Niger Med J. 2014;55:369

[27] Colak S, Gunes H, Afacan MA, Kandis H, Erdogan MO, Ayranci $M$ et al. Anaphylaxis after intramuscular injection of diclofenac sodium. Am J Emerg Med. 2014;32:815. e811815. e812

[28] Hajong R. Upper limb gangrene following intramuscular diclofenac: A rare side effect. Int J Surg Case Rep. 2013; 2013:rjs039 
[29] Dworkin RH, O'connor AB, Backonja M, Farrar JT, Finnerup NB, Jensen TS, et al. Pharmacologic management of neuropathic pain: Evidence-based recommendations. Pain. 2007;132:237-251

[30] Krenzischek DA, Dunwoody CJ, Polomano RC, Rathmell JP. Pharmacotherapy for acute pain: Implications for practice. Pain Manag Nurs. 2008;9:22-32

[31] Viscusi ER, Gan TJ, Leslie JB, Foss JF, Talon $\mathrm{MD}, \mathrm{Du} \mathrm{W}$, et al. Peripherally acting mu-opioid receptor antagonists and postoperative ileus: Mechanisms of action and clinical applicability. Anesth Analg. 2009;108:1811-1822

[32] Kristensen DM, Skalkam ML, Audouze K, Lesné L, Desdoits-Lethimonier C, Frederiksen $\mathrm{H}$, et al. Many putative endocrine disruptors inhibit prostaglandin synthesis. Environ Health Perspect. 2011;119:534
[33] Pountos I, Georgouli T, Bird H, Giannoudis PV. Nonsteroidal anti-inflammatory drugs: Prostaglandins, indications, and side effects. Int J Interferon Cytokine Mediat Res. 2011;3:1927

[34] Webb AJ, Patel N, Loukogeorgakis S, Okorie M, Aboud Z, Misra S, et al. Acute blood pressure lowering, vasoprotective, and antiplatelet properties of dietary nitrate via bioconversion to nitrite. Hypertension. 2008;51:784-790

[35] Wallace JL, Caliendo G, Santagada V, Cirino G, Fiorucci S. Gastrointestinal safety and antiinflammatory effects of a hydrogen sulfidereleasing diclofenac derivative in the rat. Gastroenterology. 2007;132:261-271

[36] Shi S, Klotz U. Clinical use and pharmacological properties of selective cox-2 inhibitors. Eur J Clin Pharmacol. 2008;64:233252

Citation: Ngozi Joseph KWOSAH, Dagogo Alexander MACPEPPLE. Comparative Effects of Single Agent Rectal Diclofenac versus its Combination with Intramuscular Pentazocine on Post Caesarean Section Pain Relief in a Tertiary Institution in Southern Nigeria. ARC Journal of Gynecology and Obstetrics. 2019; 4(2):1526. DOI:dx.doi.org/10.20431/2456-0561.0402003.

Copyright: (c) 2019 Authors. This is an open-access article distributed under the terms of the Creative Commons Attribution License, which permits unrestricted use, distribution, and reproduction in any medium, provided the original author and source are credited. 